\title{
Molecular Diagnosis of Natural Infection of Trypanosoma Congolense in a Dog in Abeokuta, Nigeria: A Case Report
}

\author{
${ }^{1}$ Abakpa, S.A.V., ${ }^{2}$ Takeet, M.I., ${ }^{3}$ Makinde, A.F., ${ }^{3}$ Adeleye, A.I. and \\ ${ }^{3}$ Adebayo, O.O. \\ ${ }^{1}$ Department of Veterinary Medicine and Surgery, \\ ${ }^{2}$ Department of Veterinary Microbiology and Parasitology, \\ ${ }^{3}$ Veterinary Teaching Hospital, College of Veterinary Medicine, Federal University of Agriculture, Abeokuta.
}

\begin{abstract}
A case of trypanosomosis was reported in a 3-year old male Rottweiler breed of dog in Abeokuta Metropolis, Nigeria. The dog was presented with clinical signs of epistaxis, bilateral corneal opacity, anorexia, vomiting brownish materials and recumbency. Haematological examination revealed high lymphocytes count, decreased red blood cells, Pack Cell Volume, haemoglobin concentration, MCH, MCHC and platelet count. Diagnosis was made using wet mount and Polymerase chain reaction (PCR) amplification of the DNA using a primer set targeting the internal transcribe spacer 1 (ITSI) of rDNA, revealed single infection with Trypanosoma congolense. The dog was treated with a single dose of diminazene aceturate at the dose rate of $3.5 \mathrm{mg} / \mathrm{kg}$ body weight, intramuscularly along with the supportive therapy. The dog recovered 9 days post therapy.
\end{abstract}

Keywords: Abeokuta, canine trypanosomosis, dog.

\section{Introduction}

African animal trypanosomosis constitutes a major impediment to livestock production and economic development in several parts of sub-Saharan Africa, including Nigeria [1,2] despite decades of attempts to control the disease and its vectors [3]. All species of Trypanosoma, with the exception of some strains of $T$. vivax which produce a hyper acute and acute infection, are characterized by high parasitemia, fever, severe anaemia and haemorrhages on the mucosal and serosal surfaces [4]. Dogs are particularly susceptible to Trypanosoma congolense, which is transmitted cyclically by Glossina species. Dogs pose a minimal risk for human infection; however, they seem to be important as a sentinel for infection [5]. Anaemia is a cardinal feature of the disease in which red blood cells are removed from the circulation by the expelled mononuclear phagocytic system. Later, in infection of several months duration, when the parasitaemia become low and intermittent, anaemia may resolve to a variable degree [4]. There are a number of effective trypanosomacidal agents for dogs including suramin, quinapyramine and diminazene but single dose of diminazene diaceturate is effective in eliminating the natural trypanosomiasis infection in canine [6]. The parasitological detection of trypanosomosis, based on detection of trypanosomes in blood of animals, has low sensitivity and is been hampered by flunctuating parasitemia [7]. In the continued efforts to explore an alternative means of diagnosing trypanosomosis, polymerase chain reaction (PCR) was found suitable and adapted for detection of trypanosome DNA using relevant primers [8].

However, there is a dearth of information on the incidence or molecular diagnosis of natural infection or disease in dogs in endemic areas of trypanosomosis such as Nigeria. This paper is to report a case of molecular diagnosis of natural infection of trypanosome in a Rottweiler in Abeokuta, Nigeria.

\section{Case History}

A 3-year old male Rottweiler dog was present to the small Animal Clinic of the Veterinary Teaching Hospital of the Federal University of Agriculture Abeokuta, with the complaint of vomiting, loss of appetite, sudden recumbency, nose bleeding and weakness, a day prior to presentation. . History revealed that the dog was acquired as a puppy within Abeokuta metropolis and that it had neither travelled out of the town nor strayed. It was the only dog in the compound.

\section{Clinical Examination And Management}

Physical examination revealed high rectal temperature $\left(40.8^{0} \mathrm{C}\right)$, tachycardia, pale mucous membrane, generalized superficial lymphadenopathy, serous ocular discharges, bilateral corneal opacity (Fig 1), generalized debility, vomiting of brownish materials and epistaxis (Fig 2). Blood sample (4ml) was collected from the dog into EDTA bottle using the cephalic vein, for wet mount, complete blood count and polymerase chain reaction. The dog was given a single dose of diminazene aceturate at dose rate of $3.5 \mathrm{mg} / \mathrm{kg}$ body weight intramuscularly 
along with supportive therapy. On day 4 post treatment, parasitological examination was carried to evaluate the level of parasitemia using Wet mount and thin blood smear methods. The complete blood count was performed using haematological auto-analyzer machine (Mindray).

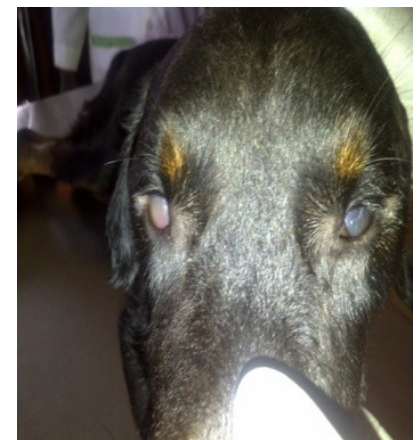

Figure 1: Dog showing corneal opacity.

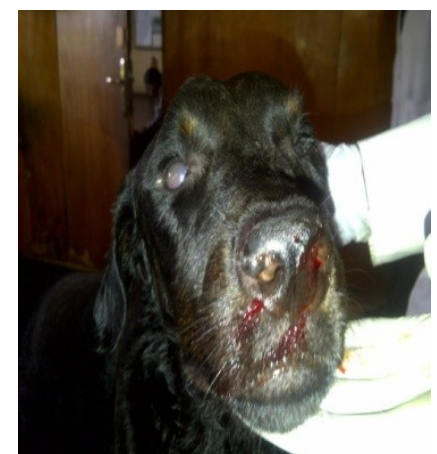

Figure 2: Dog showing epistaxis and corneal opacity

\section{DNA Extraction}

DNA was extracted from the blood in EDTA bottle using Quick-gDNA ${ }^{\mathrm{TM}}$ MiniPrep (Zymo Research Corporation, Irvine, CA 92614, U.S.A ) as described by the manufacturer. Briefly, $400 \mu \mathrm{l}$ of genomic lysis buffer was added to $100 \mu \mathrm{l}$ of blood, thoroughly mixed by vortexing for 4-6 seconds and incubated at room temperature for $5-10$ minutes. The mixture, blood and the lyses buffer, was transferred to a spin column in a collection tube and centrifuge at $10,000 \mathrm{x}$ g for 60 seconds after which the collection tube with the flow through was discarded and the spin column transferred to a new collection tube. $200 \mu \mathrm{l}$ of prewash buffer was added to the spin column and centrifuged at 10,000 x g for 60 seconds after which $500 \mu 1$ of genomic DNA wash buffer was added to the spin column and centrifuged at $10,000 \mathrm{x} g$ for 60 seconds. To elute the DNA, the spin column was transferred to a clean $1.5 \mathrm{ml}$ microcentrifuge tube and $50 \mu \mathrm{l}$ of nuclease free water was added to the spin column and incubated at room temperature for 2-5 minutes, centrifuge at $16,000 \mathrm{x} g$ for 30 seconds. The eluted DNA was stored at $-20^{\circ}$ until use.

\section{Primer Sets And Optimization}

Samples were initially tested by species-specific primers directed against multi-copy satellite repeats of each species and strains. Two sets of primers were selected for optimization based on the published work. The primer sets include TBR $1 \& 2$ [9] and ITS1 CF \& BR [10].

\section{Parasitological Detection Of Trypanosomes}

From the anti-coagulated blood, two capillary tubes were filled and sealed at one end with plasticin. The capillary tubes were spun in microhaematocrit centrifuge at 10,000 rpm for 3 minutes. After centrifugation, the buffy coat and upper most layer of red blood cells was examined as described by [11] for the presence motile trypanosomes. Not less than 50 fields were examined before positive or negative was declared for each sample. While the haematocrit centrifugation technique (HCT) positive samples were further processed as thin smear stained with Giemsa for trypanosome species identification at (x 1000 magnification).

\section{Trypanosomes Detection By Pcr}

Polymerase Chain Reaction amplification using species specific primer sets was performed in $20 \mu \mathrm{l}$ final reaction volume containing equivalent of $20 \mathrm{ng}$ of genomic DNA, $10 \mathrm{mM}$ Tris- $\mathrm{HCl}, \mathrm{pH} 8.3,1.5 \mathrm{mM} \mathrm{MgCl}_{2}$, $50 \mu \mathrm{M} \mathrm{KCl}, 200 \mu \mathrm{M}$ each of dNTPs, 40ng of each of the primers and 1unit of Thermus aquaticus DNA polymerase (Bioneer USA). The reactions were placed in MJ Mini ${ }^{\mathrm{TM}}$ Gradient Thermal Cycler (BIORAD, USA). The reaction conditions were as follows TBR $1 \& 2$; Initial denaturation at $94^{\circ} \mathrm{C}$ for 4 min followed by 35 cycles of $94^{\circ} \mathrm{C}$ for $30 \mathrm{sec}, 55^{\circ} \mathrm{C}$ for $30 \mathrm{sec}$, and $72^{\circ} \mathrm{C}$ for $30 \mathrm{sec}$; and final extension at $72^{\circ} \mathrm{C}$ for $5 \mathrm{~min}$. The multiplex primer sets, ITS1 CF \& BR were also used with initial denaturation of $95^{\circ} \mathrm{C}$ for 5 min followed by 35 cycles of $95^{\circ} \mathrm{C}$ for $1 \mathrm{~min}, 58^{\circ} \mathrm{C}$ for $1 \mathrm{~min}$ and $72^{\circ} \mathrm{C}$ for $1 \mathrm{~min}$ with final extension at $72^{\circ} \mathrm{C}$ for $10 \mathrm{~min}$. Ten microliter of the PCR products were electrophoresed through $1.0 \%$ agarose gel in $1 \mathrm{x}$ TAE (40 mM TRISacetate and $1 \mathrm{mM}$ EDTA) at $90 \mathrm{~V}$ for $60 \mathrm{~min}$ along with $10 \mu \mathrm{l}$ of biological marker, GENEMate Quanti-Marker 100 bp DNA ladder (BioExpress, UT, USA). Gels were stained with Ethidium bromide at $5 \mu 1 / 100 \mathrm{ml}$ of the agarose gel suspension. After electrophoresis, the PCR products were visualized using ultra violet transilluminator (Spectroline ${ }^{\mathrm{R}}$ TC $312 \mathrm{E}$ ) before the gels was photographed 


\subsection{Haematological values and parasitological results}

Haematology revealed high lymphocytes (31.6\%), decreased red blood cells $\left(4.83 \times 10^{12} / \mathrm{L}\right)$, haemoglobin concentration 8g/L, PCV (32\%), MCH $(16.5 \mathrm{pg})$, MCHC $(246 \mathrm{~g} / \mathrm{L})$ and platelet count $\left(27 \times 10^{9} / \mathrm{L}\right)$. Examination of the buffy coat revealed a sluggishly moving trypanosome and the Giemsa stained smear made from the second buffy coat from the second capillary tube revealed trypanosomes with marginally paced kinetoplast.

\subsection{Gel electrophoresis and Polymerase Chain Reaction (PCR)}

Agar rose gel electrophoresis of the PCR products revealed a band size of about 700bp (Fig. 3)

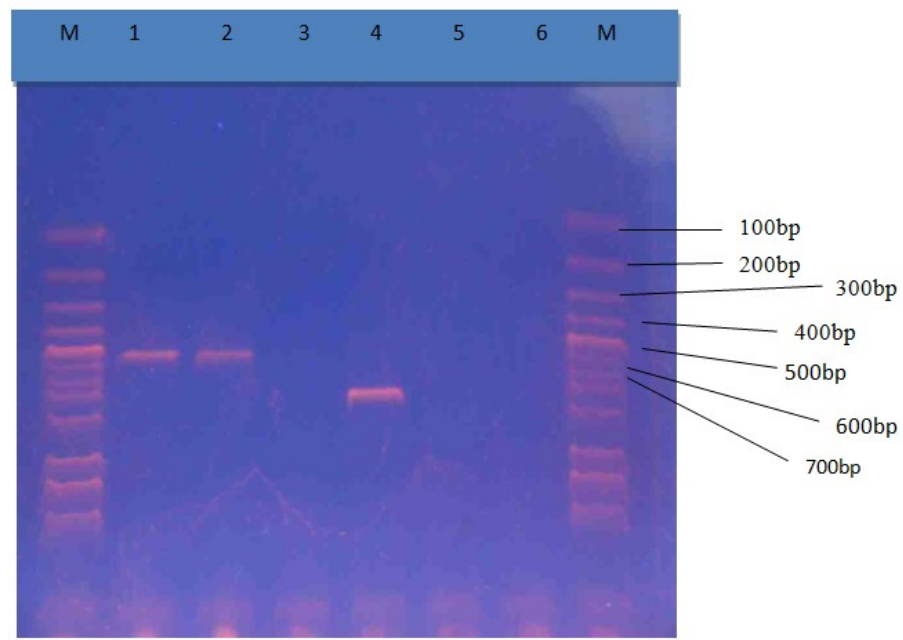

Figure 3: Electrophoresis analysis of the PCR product Trypanosomes

M: Molecular marker

1-2: Trypanosoma brucei, 3-5: Trypanosoma congolense, 6: Negative control

\section{Discussion}

Canine trypanosomosis is a disease which its prevalence in Nigeria has been neglected in Nigeria. The frequency of re-emerging unpublished field cases call for concern. The clinical signs observed in this case were, high temperature $\left(40.8^{0} \mathrm{C}\right)$, pale mucous membrane, bilateral corneal opacity, epistaxis, splenomegaly, lymphadenopathy and generalized debility. These observations were in agreement with the findings of [6] who reported $T$. evensi organism in peripheral blood with history of inappetence, dullness and persistent fever for five days and bilateral corneal opacity which is a characteristic finding in chronic trypanosomiasis [12]. Anaemia, though not pathognomonic, is common feature in trypanosomosis. In this case, the Red Blood Cells, Pack Cell Volume, haemoglobin concentration, mean corpsuscular haemoglobin, mean corpsuscular haemoglobin concentration and platelet were decreased. The results of the present study were similar to the observations of [13] who studied clinical hematology of canine chagas disease in Texas and reported decreased Packed Cell Volume and also recorded hypoproteinemia, hypoalbuminemia and thrombocytopenia. The diminazene aceturate given intramuscularly once at a dosage of $3.5 \mathrm{mg} / \mathrm{kg}$ was effective and the parasitemia was cleared on day 4 post therapy. Similar results were recorded by [6] who treated trypanosomosis in Pomeranian dog with a single dose of diminazene aceturate.

\section{Conclusion}

In conclusion, canine trypanosomosis may be prevalent among dogs in Nigeria and elsewhere than reported. We recommended that veterinarians in the field should endeavour to rule out canine trypanosomosis when diagnosing infection due to haemoparasites.

\section{References}

[1]. J.N. Abenga,, F.N.C. Enwezor, F.A.G. Lawani, C. Ezebuiro, J. , Sule and K.M. David, Prevalence of trypanosomosis in trade cattle at slaughter in Kaduna, Nigeria. Nig. J. Parasitol 23, (2002), 107-110.

[2]. A.A. Ilemobade, Tsetse and trypanosomosis in Africa: the challenges, the opportunities. Ondersteport Journal of Veterinary Research 76, (2009), 35-40.

[3]. D.H. Molyneux, African Trypanosomosis. Failure of Science and Public Health in the African Trypanosomes. In: World Class Parasites, Vol. 1. (Black S. J., J. R. Seed, Eds.), Kluwer Academic Publishers, Dordrecht, (2001), pp. 1-10. 
[4]. G.M. Urquhart, J. Armour, J.L. Duncan, A.M. Dunn and F.W. Jennings, Veterinary Parasitology. 2nd Ed. Blackwell Science Co. UK. (2002), pp.217.

[5]. C.E. Greene, Trypanosomiasis. In Infectious Disease of the Dog and Cat. $3^{\text {rd }}$ edn. W.B. Saunders. (2006) pp676-685

[6]. N.L. Rani and K. Suresh, Canine trypanosomiasis. India Veterinary Journal 84: (2007) 186-187.

[7]. B.B. Kayang, K.M. Bosompem and R.K. Assoku, Detection of Trypanosoma brucei, T. congolense and T. vivax infections in cattle, sheep and goats using latex agglutination. Int J Parasitol 27(1) (1997):83-7.

[8]. L. Penchenier, G. Simo, P. Gre'baut, S. Nkinin, C. Laveissie're and S. Herder, Diagnosis of human trypanosomiasis, due to Trypanosoma brucei gambiense in central Africa, by the polymerase chain reaction. Trans. Roy. Soc. Trop. Med. Hyg. 94, (2000) 392-394.

[9]. P. Sloof, L.B. Johannes, F.J.M. Konings, H.H. Menke, P. Borst, W.E. Gutteridge and L. Wilson, Characterization of Satellite DNA in Trypanosoma Brucei and Trypanosoma cruzi. J. Mol. Biol. 167: (1983), 1-21.

[10]. Z.K. Njiru, C.C. Constantine, S. Guya, J. Crowther, J.M. Kiragu, R.C.A. Thompson and A.M.R. Davila, The use of ITS1 rDNA PCR in detecting pathogenic African Trypanosomosis. Parasitol. Res 95: (2005), 186-192

[11]. M. Murray, P.K. Murray, and W.I.M. McIntyre, An improved parasitological technique for the diagnosis of African trypanosomiasis. Transactions of the Royal Society Tropical Medicine and Hygiene 71, (1977) 325-326.

[12]. P.S. Thirunavukkarasu, V.V. Rao, S.R. Srinivasan, A.P. Nambi, and P. Dhanapalan, India Journal of Veterinary Medicine, 24: (2004), 117.

[13]. S.A. Kjos, K.F. Snowden, T.W. Craig, B. Lewis, N. Ronald, J.K. Olson, Distribution and characterization of canine chagas disease in Texas. Veterinary Parasitology 152: (2008) 249-256 